\title{
THE AVIGNON BRIDGE: A 3D RECONSTRUCTION PROJECT INTEGRATING ARCHAEOLOGICAL, HISTORICAL AND GEMORPHOLOGICAL ISSUES
}

\author{
M. Berthelot ${ }^{\text {a }}$, N. Nony ${ }^{\text {a }}$ L. Gugi ${ }^{\text {a }}$, A. Bishop ${ }^{\text {a }, \text { L. De Luca }}{ }^{\text {a }}$ \\ ${ }^{a}$ CNRS MAP (UMR 3495 CNRS/MCC), Marseille, France (nno, lgu, abi, ldl)@map.cnrs.fr
}

Commission V, WG V/4

KEY WORDS: 3D digitisation, data integration, virtual reconstruction, hypothetical representation

\begin{abstract}
:
The history and identity of the Avignon's bridge is inseparable from that of the Rhône river. Therefore, in order to share the history and memory of the Rhône, it is essential to get to know this bridge and especially to identify and make visible the traces of its past, its construction, its interaction with the river dynamics, which greatly influenced his life.

These are the objectives of the PAVAGE project that focuses on digitally surveying, modelling and re-visiting a heritage site of primary importance with the aim of virtually restoring the link between the two sides which, after the disappearance of the Roman bridge of Arles, constituted for a long time the only connection between Lyon or Vienna and the sea.

Therefore, this project has an important geo-historical dimension for which geo-morphological and paleoenvironmental studies were implemented in connection with the latest digital simulation methods exploiting geographic information systems. By integrating knowledge and reflections of archaeologists, historians, geomorphologists, environmentalists, architects, engineers and computer scientists, the result of this project (which involved 5 laboratories during 4 years) is a 3D digital model covering an extension of 50 $\mathrm{km} 2$ achieved by integrating satellite imagery, UAV-based acquisitions, terrestrial laser scanning and photogrammetry, etc.

Beyond the actions of scientific valorisation concerning the historical and geomorphological dimensions of the project, the results of this work of this interdisciplinary investigation and interpretation of this site are today integrated within a location-based augmented reality application allowing tourists to exploring the virtual reconstruction of the bridge and its environment through tablets inside the portion of territory covered by this project (between Avignon and Villeneuve-lez-Avignon). This paper presents the main aspects of the $3 \mathrm{D}$ virtual reconstruction approach.
\end{abstract}

\section{INTRODUCTION}

Despite its cultural and tourist notoriety, Avignon bridge still remains a relatively unknown architectural site. From a historical and archaeological point of view, very few research have focused on the story of its raising. The only knowledge about its history just underlines its legendary origins (Marié, 1953): “...En 1177, a shephered called Benezet was asked by god to undertake the building of a bridge across the river..." According to this story, the bridge was achieved 8 years later, in 1185 .

The purpose of the PAVAGE project was to understand the real chronology of the bridge: when was it built? What was its original shape? Why was it finally abandoned, whereas some bridges built at the same period and in the same area are still active today?

The study of Saint-Benezet Bridge needed to expand the research fields beyond the traditional archaeological and architectural studies. Indeed, a bridge is a specific architectural element as it takes place into a landscape that determines its shape and evolution. Insofar as it takes a role of link between two territorial spaces, its analysis cannot be conducted without a study of its economic and politic context.

The issues raised by this study needed the collaboration of four research teams: geomorphologists for the landscape (CEREGE, Aix-en-Provence), historians for the social and economic context (CIHAM, Avignon), building archaeologists that focused on the bridge itself and the adjoining buildings (LAMMM, Aix-en-Provence), architects, engineers and 3D specialists for elaborating a rich and structured 3D representation of the bridge at several scales and temporal states (MAP, Marseille); plus the Avignon's Archives Service for gathering documentary resources on the topic. In this short paper we'll focus on the main aspects of our 3D virtual reconstruction approach, including the integration of multiple data coming from different domains, at different scales and in different formats.

\section{REALITY-BASED 3D DIGITISATION AND RECONSTRUCTION}

\subsection{Collecting data in a web data base}

The first task was to gather all the actual knowledge related to the bridge and its surroundings within a database shared between the whole research team.

The data gathering allowed to bring to light unpublished documents, both illustrated and textual, from medieval to contemporary times. In order to classify and share all the documentary sources according to relevant criteria, we built an on-line database based on PHP/MySQL (see figure 1) allowing researchers involved in the project to upload, document, comment and download documentary sources (texts, iconography, etc..) according to their specific study's object. 
The continuous access to these documents was very helpful for the $3 \mathrm{D}$ virtual reconstruction issues, as they described - even sometimes in a very precise way - the former appearance of the area at several scales and temporal states.

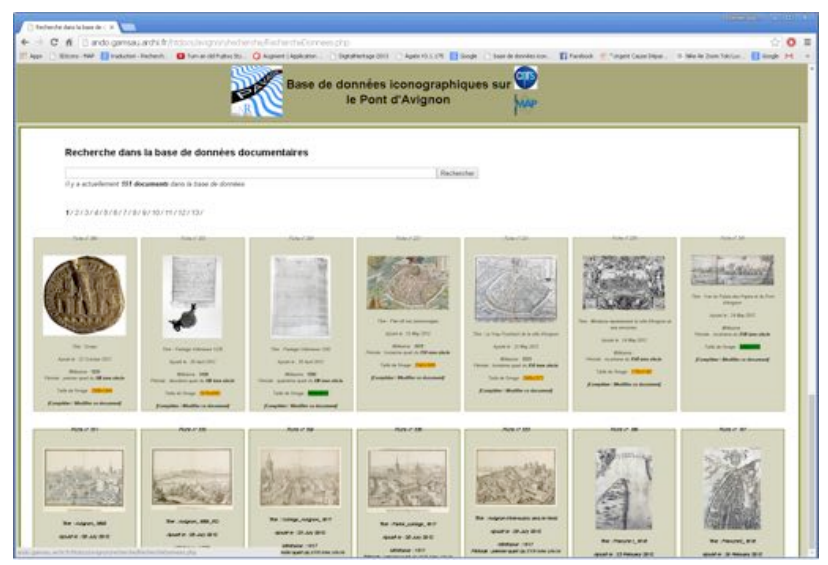

Figure 1. The developed on-line database for archiving and sharing all the documentary sources related to the Avignon's Bridge

Actual documents, such as IGN (Institut Géographique National) aerial orthoimages, topographical surveys from the CNR (Compagnie Nationale du Rhône), etc. were also added to this corpus.

These documents were digitised, geo-referenced and integrated into the used GIS system (ESRI ArcGIS). This overlapping of heterogeneous data (in terms of period, iconography and thematic nature), was a decisive step for programming and carrying out all the on-field investigations. As example the figure 2 shows the overlapping of an ancient map (Carte du Rhône à Villeneuve - J-F de MONTAIGU - 1685) with the CNR survey (in 1969) unveiling some inconsistences concerning the number of bridge's piers to be taken into account for the 3D virtual reconstruction.

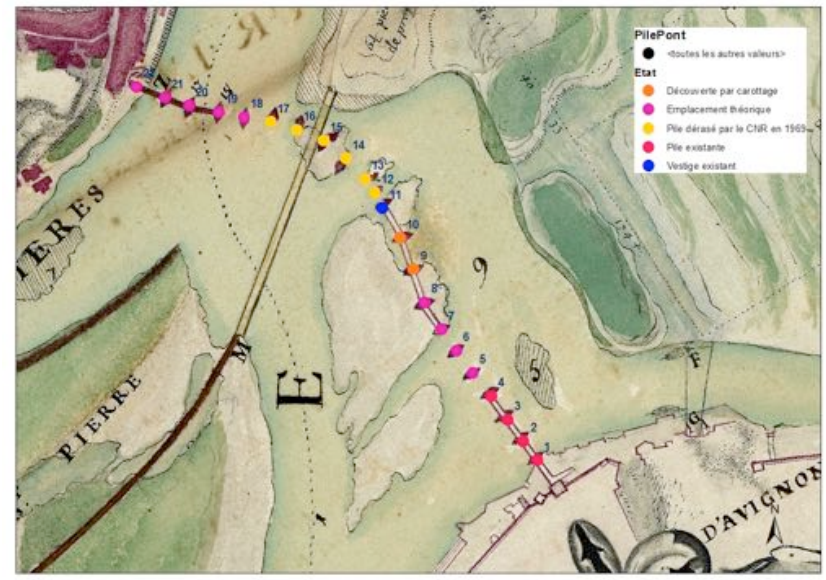

Figure 2. Overlapping of an ancient map (Carte du Rhône à Villeneuve - J-F de MONTAIGU - 1685) with the CNR survey of the piers remains in 1969

\subsection{Multi-scales and multi-sensors surveying}

With the aim of analysing and representing the environment surrounding the Bridge (50 square kilometres) various surveying techniques were integrated according to the morphological complexity levels to be observed and analysed: terrestrial 3D laser scanning, terrestrial and UAV-based photogrammetry, GPS, Coring, ERT surveying and acoustic river surveying.

\subsubsection{D laser scanning}

Four 3D laser-scanning campaigns (based on time-of-flight and phase-shift technologies) were carried out on the main architectural elements: the bridge itself; the Saint-Benezet church on its second pier; the "Philippe le Bel" tower, on which the bridge ended up on Villeneuve side; the castle on the Avignon side. A GPS campaign allowed gathering these surveys into a unique geo-referenced system.

\subsubsection{Photogrammetric survey}

The photogrammetric campaign was carried out with the aim of providing archaeologists with precise and accurate 2D data. By starting from the application of accurate and rigorous acquisition protocols (Martin-Beaumont et al., 2013), the image processing was based on Apero/MicMac pipeline (PierrotDeseilligny et al., 2011) with the aim of generating dense and coloured point clouds (see Figure 3), orthoimages (see Figure 4) and depth maps of all the relevant buildings facades.
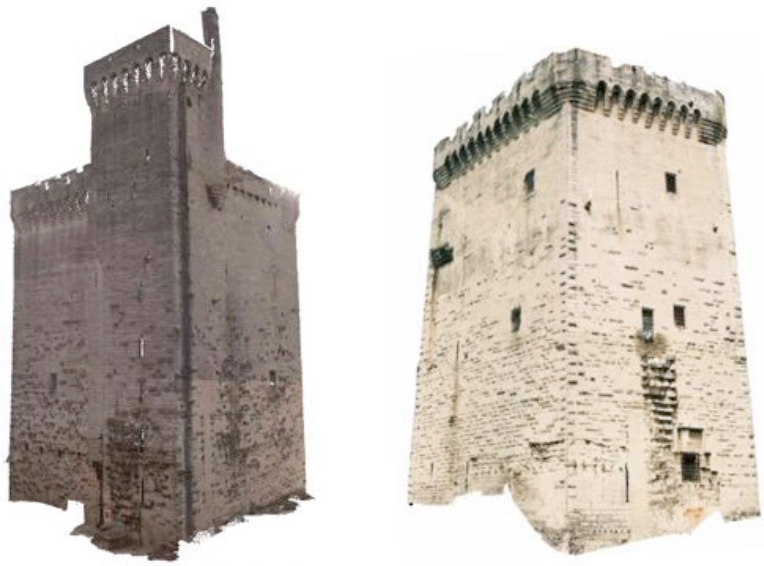

Figure 3. Coloured point clouds of Tour Philippe le Bel created by image matching with Apero/MicMac

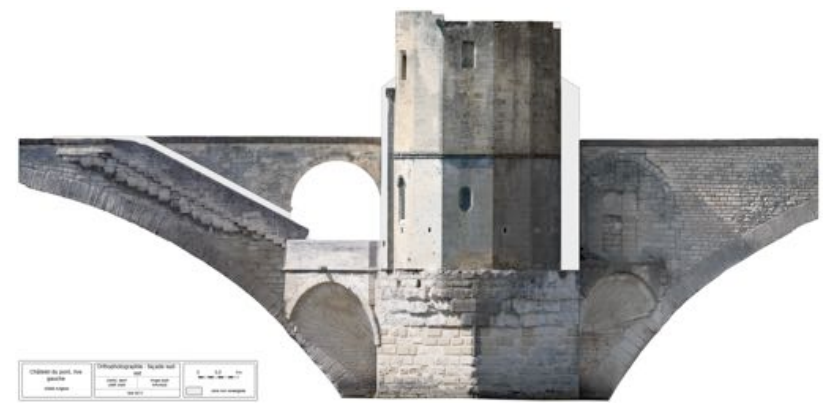

Figure 4. Orthoimage of east façade of Saint-Bénézet Church, generated with Apero/MicMac starting from images acquired from a boat.

A UAV-based photogrammetric campaign was also leaded on the bridge surroundings, on Villeneuve side. The purpose was to generate a 3D model of the hill close to the former ending bridge (Figure 5). 


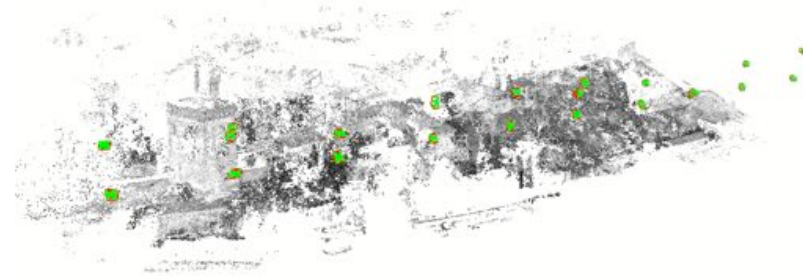

Figure 5. Sift point cloud and aerial image orientation of Tour Philippe le Bel surroundings, with Apero

\subsubsection{Bathymetric surveying}

The CEREGE team carried out a bathymetric surveying campaign (Vella et al., 2013) by basing on a CNR survey of the piers remains in 1969 (before their definitive destruction). Its purpose was to confirm the position (and the approximate shape) of these remains. This survey was made by acoustic camera at a resolution of $10 \mathrm{~cm}$.

By starting from the elevations detected on the bottom of the river, a geo-referencing step allowed to define the relevant borders of the underwater remains of the bridge (see figure 6).
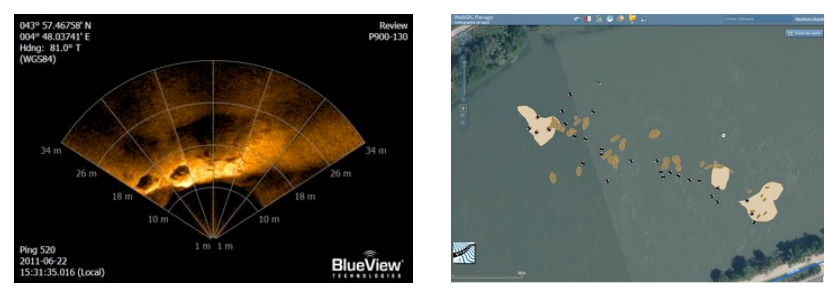

Figure 6. Acoustic camera results, showing the piers residues

\subsubsection{Corings}

The comparison between geo-referenced ancient maps - mainly Montaigu land registers - and actual ones permitted to identify areas in which corings would be carried out:

A first campaign was carried on the estimated piers position. Four corings have been made, that confirmed the presence of two piers. A carbon dating made on wood residuals allowed to estimate the age of the layer around 1285 .

A drilling was also made on the Villeneuve side, in order to determinate the underground composition at the estimated former river bed

\subsection{An integrated 3D reconstruction approach}

The large amount of the gathered data, mainly 3D pointclouds, was post-processed in order to generate intelligible 3D models. The four remaining bridge arches, Saint-Bénézet chapel, as well as Philippe le Bel tower and Avignon castle was thus digitised, following some common interactive geometric modelling techniques (profile extraction, extrusion, primitive adjustment, etc.) for a point-cloud based 3D reconstruction.

This step was essential to provide archaeologists and architects with accurate and handleable geometric models. The models were detailed, according to the research advance and the objects relevance.

\subsection{Data gathering in a GIS datawarehouse}

All these data were geo-referenced and integrated into a H-GIS (Historical GIS). By integrating such heterogeneous data, in terms of space and time, this database permitted to enhance knowledge and analysis capacity of each document. Thus, the GIS became, besides a way to synthetize data, an important support for the scientific analysis.

The gathered documents were processed according to their nature. Ancient maps were vectorised (land use, urban weft, foot print of remarkable buildings, etc.). Ancient drawings were replaced in the estimated original position and orientation. This allowed to check, by comparing the elements represented on the drawing to the different maps and other drawings, the reliability of the artist.

\section{HYPOTHETICAL RECONSTRUCTION}

The hypothetical reconstruction focused on two periods: middle $14^{\text {th }}$ and $17^{\text {th }}$ century and covers a 50 square kilometres area around the bridge. This choice was made in order to show two different aspects of the bridge: 1350 corresponds to a (estimated) high activity period, whereas 1650 tally with its end of use (it is definitively abandoned in 1685).

\subsection{Ancient Rhône and landscape restitution}

The former landscape restitution was made by stacking former maps and actual. By adding the on-field acquired data during the coring campaigns, two DEM were built as depth maps. These models were then transformed into meshes, and post processed with digital sculpting (ZBrush) software (see Figure 7), in order to get a more realistic appearance and UV coordinates. Subsampled models extracted from original ones have finally been generated and added to the GIS.
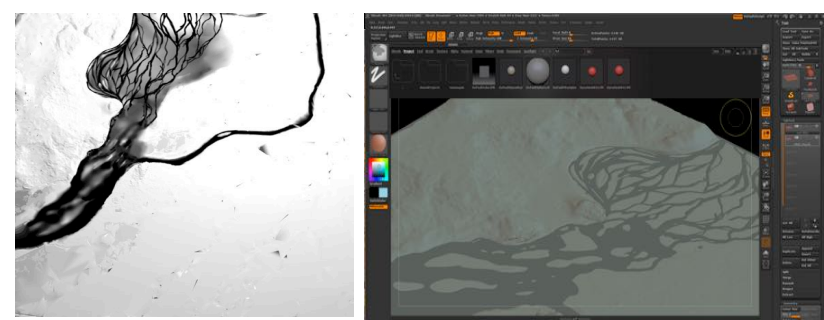

Figure 7. The creation of the ancient landscape, from depth map to $3 \mathrm{D}$ model

The missing parts of this study were extrapolated from available data and geologist analysis, the accuracy and density decreasing as moving away from the bridge.

This work has highlighted the modifications that affected the river during the last seven centuries: at the bridge origin, it was essentially made of meanderings, with low flow and small peeble islands - like Durance river today, close to Avignon. Its flow and level were then increased, and the meanderings changed into large channels separated by islands (Vella et al., 2013).

\subsection{The Bridge}

The research on the bridge itself has been splitted into two parts: its architecture and its path. In order to modify the geometric generation path, according to the archaeological research progress, without modifying the whole digital reconstruction, an animation technic was used: the bridge was skinned by means of 22 bones, each one controlling the position and orientation of one arch (Figure 8). Thus, moving one or more arches was very handy, as the whole bridge was connected to the moving parts. This allowed to better control the parametric relationships between parts and subparts of the overall geometry. 

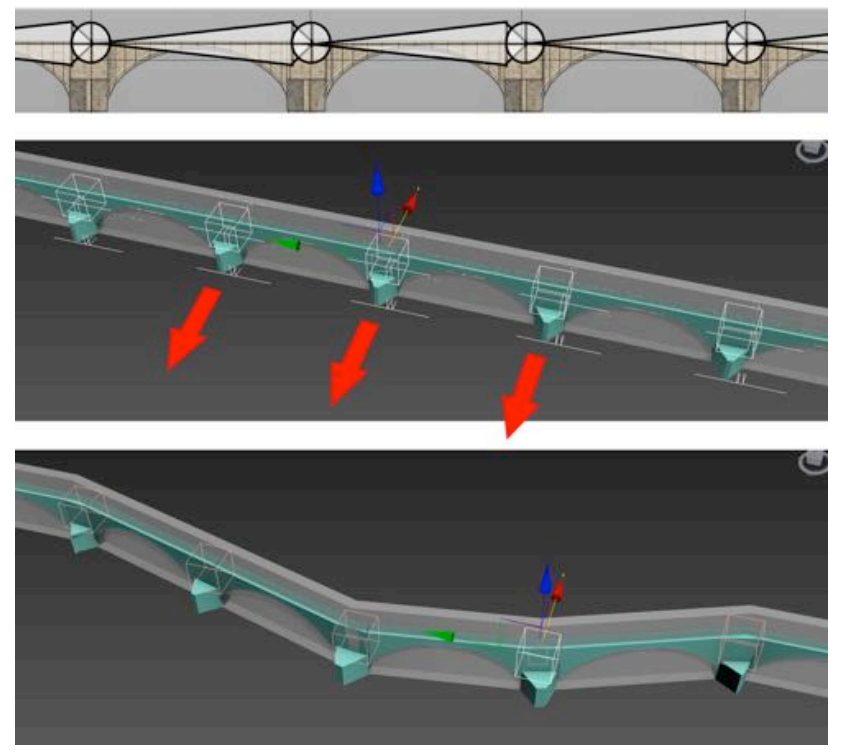

Figure 8 . The bones system, created to control the bridge's path

\subsection{Buildings}

The surroundings buildings reconstruction was the subject of an intense collaboration between archaeologists and 3D modellers. This study was based on the $3 \mathrm{D} / 2 \mathrm{D}$ surveying campaigns: $3 \mathrm{D}$ models of the actual state state and "pierre à pierre" surveys extracted from orthoimages. This data, combined to the large amount of ancient pictures, and many round trips between 3D models and archaeologists (Figure 8) permitted to build for each building 3 or 4 different temporal states, from the middle $14^{\text {th }}$ century to the $18^{\text {th }}$.

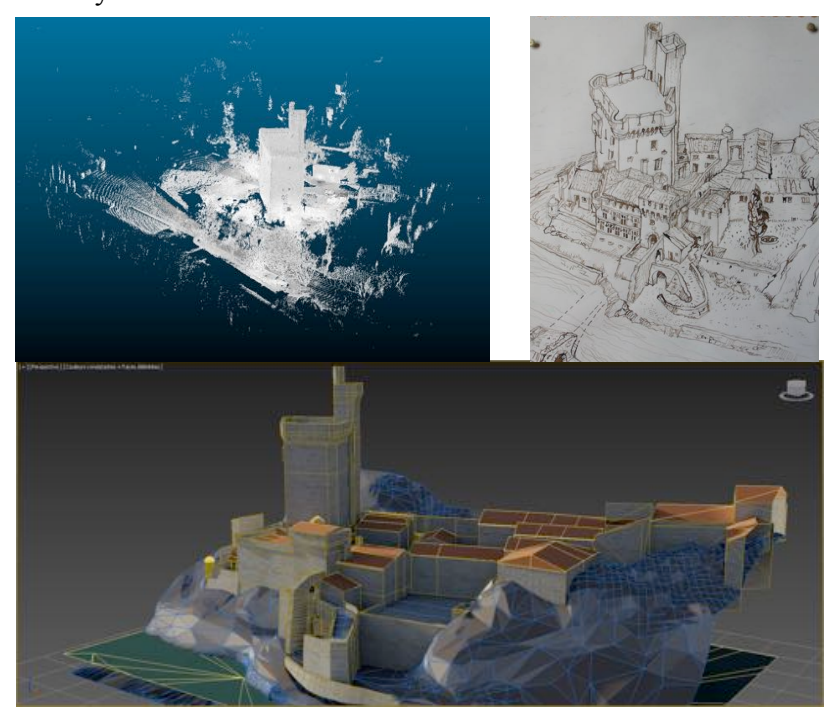

Figure 9. The 3D hypothetical reconstruction of the "Tour Philippe le Bel", based on laser scanner surveying and archaeological analysis

\subsection{Urban spaces procedural modelling}

Avignon and Villeneuve, as well as surrounding rural group settlements were represented using procedural modelling methods (City Engine; see Figure 9). This work was based on vectorised ancient maps. Urban weft was used as guides for the houses generation.

Geographers and historians established a series of criteria for defining morphological parameters by basing on the description of a set of basic typologies: roof inclination, window distribution, façade size, etc.

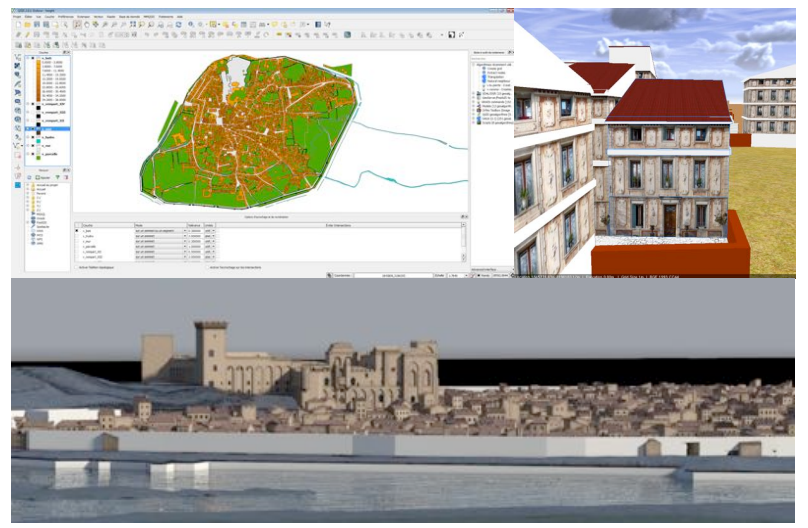

Figure 10. Procedural modelling of houses, based on urban wefts and architectural typology at the reconstruction time

\subsection{Final 3D model}

All this data, covering multiple representation scales and geometric levels of detail, were integrated within a unique referential using 3DsMax. This choice was essential for managing, visualising and processing a so complex 3D model. The main architectural elements were processed again in order to improve the final visual appearance of the surfaces: $3 \mathrm{~d}$ details, textures, etc. Two overlapped 3D models were gathered, covering two periods (1350 and 1650).

\section{FINAL OUTPUTS}

Many 3D renderings were elaborated during the project, describing various aspects of the archaeological and geological reconstruction. Different rendering types were used, from realistic ones to wireframe, as well as some overlapping between ancient iconography and correspondent viewpoints on 3D models. All these images have been used as support for reasoning about the hypothetical reconstructions, as well as for improving the graphic environment of the final 3D scene by adding natural elements by post-production techniques.

The project achieved with a four minutes film, composed by two parts: one camera's path from Avignon to Villeneuve, and one in the opposite way. This video needed a full adaptation of the entire 3D scene in order to improve the photorealistic look of the final rendering. The buildings were detailed with highresolution textures and various effects (flowing river, vegetation, etc.) were added (see figures 11 and 12). Due to the size and render settings (for the production of a HD video), the sequences of images were processed using renderfarms.

Finally, an augmented reality application (Avignon 3D), available for free on AppleStore and Google Play for smartphones and tablets, has been created by Art Graphique \& Patrimoine starting from the above presented 3D scenes. It is based on 6 panoramic renders, located on both sides of the river, and on the Barthelasse island. The user can switch, for each point of view, between three different temporal states: 1350 , 1650 and today. The application is improved by audio and video 
content, in which scientists involved in the project describe various technical aspects related to the project and the bridge itself.

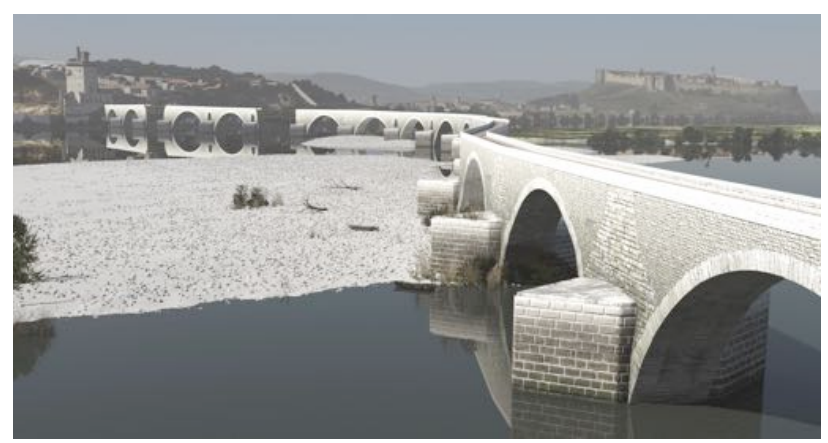

Figure 11. The final render of the Bridge, from Avignon side, in its hypothetical state in 1650 .

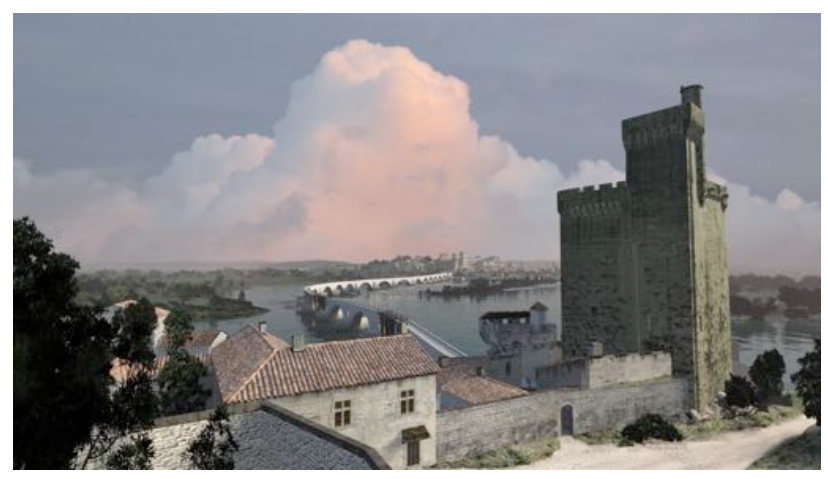

Figure 12. The final render of the Bridge, from Villeneuve side, in its hypothetical state in 1650 .

\section{CONCLUSIONS}

This project, achieved in December 2014, required four research teams, during three years. It is a good example of how various research fields can cooperate and share information related to an exceptional heritage artefact. A lot of data was gathered and created, with different nature (more than 5000 images, 150 laser scanner stations, two $1 \mathrm{~Gb} 3 \mathrm{D}$ models, 300 archive pictures, etc.).

Various techniques, from on-field 2D/3D acquisition to geological searches have also been used, according to the different research teams involved.

The purpose, as explained in this paper, was both scientific and didactic: the results have been consistently shown to the public by means of various medias: exhibitions, movies, and so on.

On the other side, scientific results - a high definition 50 square kilometres 3D model and a webGIS - are still available for possible future researches.

\section{ACKNOWLEDGEMENTS}

On the memory of Michel Berthelot (1948-2014), the first author of this paper.

\section{REFERENCES}

Martin-Beaumont et al., 2013. Martin-Beaumont N., Nony N., Deshayes B., Pierrot-Deseilligny M., De Luca L. Photographerfriendly workflows for image-based modelling of heritage artefacts. Archives of the Photogrammetry, Remote Sensing and Spatial Information Sciences, XXIV International CIPA Symposium, Strasbourg, France, 2-6 September 2013.

Pierrot-Deseilligny et al., 2011. Pierrot-Deseilligny M., De Luca L., Remondino F. Automated Image-Based Procedures for Accurate Artifacts 3D Modeling and Orthoimage. Proceedings of XXIIIth International CIPA Symposium, Prague, Czech Republic, September 12 - 16, 2011

Vella et al., 2013. Vella M.A, Ghilardi M., Diouf O., Parisot J.C., Hermitte D., Provansal M., Fleury J., Dussouillez P., Sabatier-Delanghe D., Demory F., Hartmann-Virnich A., Delpey Y., Berthelot M., Bicket A. Géoarchéologie du Rhône dans le secteur du pont Saint-Bénézet (Avignon, Provence, France) au cours de la seconde moitié du deuxième millénaire apr. J.-C.: approche croisée de géographie historique et d'étude paléoenvironnementale. Géomorphologie, Relief, Processus et Environnement, 3, 287-310.

Marié, D.M., 1953. Le pont Saint-Bénézet, premier volume. Histoires et Réalité, 1953. 